\title{
ANALISIS SEBARAN PETIR CLOUD TO GROUND (CG) DI WILAYAH JABODETABEK PADA TAHUN 2016
}

\author{
Jaka Anugrah Ivanda Paski ${ }^{1, a)}$, Yusuf Hadi Permana ${ }^{1, b)}$, Dyah Ajeng Sekar Pertiwi ${ }^{2)}$ \\ ${ }^{1}$ Puslitbang BMKG, Jl. Angkasa I No. 2, Jakarta Pusat 10720 \\ ${ }^{2}$ Stasiun Meteorologi Raden Inten II, Jl. Alamsyah Ratu Prawira Negara Lampung Selatan 35362 \\ Email: a)jaka.paski@yahoo.com, b)yusuf_hadi_perdana@yahoo.com
}

\begin{abstract}
Abstrak
Petir merupakan peristiwa elektrifikasi yang terjadi akibat pembuangan muatan induksi bertegangan tinggi dari awan Cumulonimbus. Muatan induksi dapat terjadi antar sesama awan (Cloud to Cloud) maupun antara awan dengan tanah (Cloud to Ground). Proses penyambaran petir ke tanah selalu menempuh jarak terpendek dengan hambatan listrik terkecil. Sambaran petir dapat menimbulkan dampak serius seperti kerusakan rangkaian elektronik, gangguan telekomunikasi dan korban jiwa. Penelitian ini bertujuan untuk menganalisis secara spasial dan temporal karaktersitik sambaran petir Cloud to Ground (CG) di wilayah Jabodetabek dalam waktu satu tahun. Penelitian bermanfaat untuk pemetaan daerah dan waktu rawan kejadian sambaran petir. Data yang digunakan diperoleh dari rekaman citra lightning detector yang dioperasikan oleh BMKG pada tahun 2016. Metode analisis kerapatan sambaran petir dikelompokkan dalam periode musim per tiga bulan yaitu Desember-Januari-Februari (DJF), Maret-April-Mei (MAM), Juni-Juli-Agustus (JJA). Rekaman citra lightning detector juga divalidasi dengan citra radar cuaca BMKG Tangerang pada hari kejadian sambaran petir terbanyak. Hasil analisis menunjukkan bahwa puncak sambaran CG terjadi pada periode MAM di sekitar wilayah Bogor.
\end{abstract}

Kata-kata kunci: cloud to ground, petir, lightning detector.

\begin{abstract}
Lightning is an electrical event that occurs due to high-voltage, induced charge discharges from Cumulonimbus clouds. An induced charge may occur between clouds (Cloud to Cloud) or between clouds and ground (Cloud to Ground). The process of lightning discharge to the ground always travels the shortest distance with the smallest electrical resistance. Lightning strikes can have serious consequences such as electronic circuit breakage, telecommunication interruptions and fatalities. This study aims to analyze spatial and temporal characteristic of Cloud to Ground (CG) lightning strikes in the Jabodetabek area within one year. Research is useful for mapping the area and time prone to lightning strike events. The data used are obtained from the lightning detector image recorder operated by BMKG in 2016. The method of lightning strike density analysis is grouped in the three-month period of December-January-February (DJF), MarchApril-May (MAM), June - July-August (JJA). Lightning detector image recording is also validated with BMKG Tangerang weather radar image on the day of the greatest lightning strike event. The analysis results show that the peak of CG strike occurred in the MAM period around the Bogor area.
\end{abstract}

Keywords: cloud to ground, lightning, lightning detector. 


\section{PENDAHULUAN}

Petir merupakan gejala listrik alami dalam atmosfer. Petir didefinisikan sebagai pelepasan muatan lisirik dengan arus yang cukup tinggi dan bersifat sangat singkat yang biasanya terjadi pada saat awan Cumulunimbus (Cb) [1]. Dalam definisi lain, petir merupakan pelepasan muatan elektrostatis disertai dengan pancaran cahaya dan radiasi elektromagnetik lainnya. Awan yang berpotensi menimbulkan petir adalah awan Cumulonimbus yang tumbuh akibat pemanasan tinggi di permukaan bumi. Pemanasan di permukaan bumi ini mendorong uap air naik ke atas dengan cepat. Oleh karena itu, ciri-ciri awan Cumulonimbus adalah bentuknya yang menggumpal seperti kapas dan membubung tinggi di langit [2].

Pelepasan muatan pada petir terdapat beberapa jenis yakni pelepasan muatan dari awan ke permukaan tanah atau Cloud to Ground (CG), pelapasan muatan antar awan yang dikenal dengan Cloud to Cloud (CC), pelepasan muatan dari awan ke udara sekitar yang disebut dengan Cloud to Atmosphere (CA) dan pelepasan muatan dalam awan atau Intra Cloud (IC) [3].

Pelepasan muatan dari awan ke permukaan tanah (CG) merupakan jenis petir yang berdampak langsung terhadap aktivitas manusia. [4]

Terdapat 3 jenis muatan yaitu netral, postif dan negatif. Petir CG negatif (-) lebih umum daripada petir CG positif (+), karena awan biasanya bermuatan negatif di bagian dasar awan dan muatan positif berada di dekat bagian atas sehingga muatan elektron yang terlepas. Dalam prosesnya, produksi sambaran petir CG negatif berasosiasi dengan presipitasi konvektif dan CG positif berhubungan dengan anvil dan presipitasi statiform [5].

Daerah Jakarta dan sekitarnya atau yang dikenal dengan Jabodetabek (Jakarta, Bogor, Depok, Tangerang dan Bekasi) memiliki bentang alam atau topografi yang berbatasan dengan laut Jawa di sebelah utara dan pegunungan di sebelah selatan. Kondisi topografi sangat mempengaruhi kerawanan sambaran petir jenis CG [6]. Kondisi topografi dengan bentuk curam cenderung dapat mengangkat uap air sehingga terbentuk awan-awan konvektif terutama Cumulonimbus (Cb) [7]. Perbukitan merupakan salah satu yang dapat memaksa pengangkatan uap air yang cukup banyak dari laut yang menjadi awan konvektif [8][9].

Selain faktor topografi, daerah Jabodatabek merupakan pusat pertumbuhan ekonomi Indonesia sehingga perkembangan wilayah perkotaan sangat pesat. Banyaknya bangunan-bangunan tinggi dan pabrik-pabrik dibangun dan sangat riskan terkena sambaran petir. Oleh karena kondisi wilayah Jabodetabek yang sangat strategis, dilakukan penelitian mengenai kejadian sambaran petir dengan mengambil kasus pada tahun 2016 dengan melihat 3 musim yang terjadi di Indonesia. Tujuan dari penelitian ini adalah untuk memetakan secara spasial dan temporal kejadian sambaran petir yang terjadi di wilayah Jabodetabek agar dapat dimanfaatkan untuk pengetahuan dan peringatan daerah rawan bahaya sambaran petir.

\section{METODE PENELITIAN}

Data yang digunakan adalah data rekaman aktivitas petir yang dideteksi oleh sensor Direction Finding Antena. Sensor mendeteksi gelombang elektromagnetik dengan frekuensi $10 \mathrm{kHz}$ hingga $200 \mathrm{kHz}$ yang dipancarkan oleh petir. Sinyal yang diterima sensor kemudian diterjemahkan oleh PCI Card Storm Tracker untuk membedakan jenis petir yang terjadi. Data Dipole Mode Index (DMI) dan Indeks Nino 3.4 dari Berau of Meteorology (BoM). Data radar cuaca yang digunakan merupakan data dari radar cuaca C-Band BMKG Tangerang.

Prinsip kerja dari Storm Tracker adalah mendeteksi sinyal radio yang dihasilkan oleh sambaran petir yang dihasilkan oleh sambaran petir (10 kHz sampai $200 \mathrm{kHz})$ dan menggunakan antena Direction Finding untuk menentukan arah datangnya petir [10]. Analisis software menyaring gangguan dan membuat informasi sambaran agar hasil didapatkan lebih akurat. Hasil rekaman kejadian petir selanjutnya ditampilkan pada program monitor LD/2000. Alur perekaman kejadian petir oleh sistem Lightning Detector ditunjukkan oleh gambar 1. 


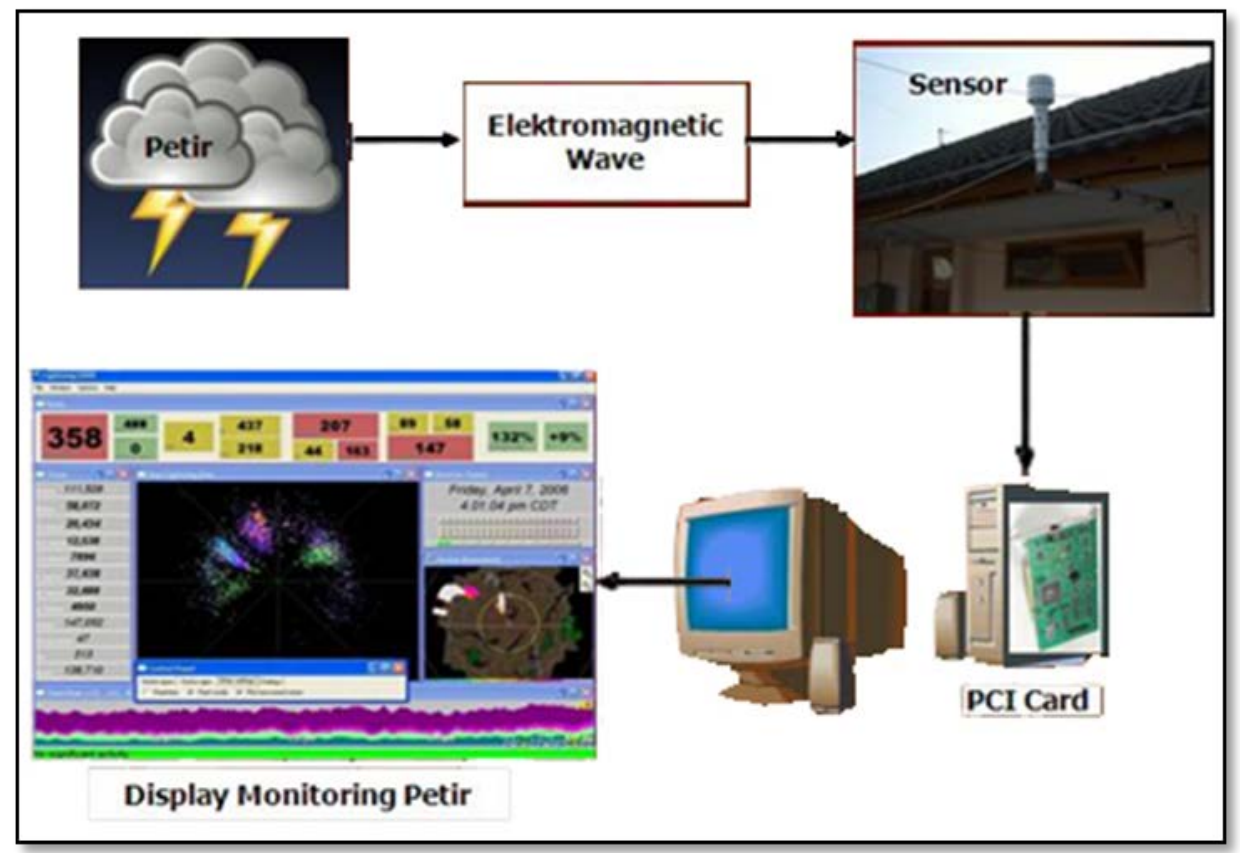

GAMBAR 1. Mekanisme perekaman aktivitas petir oleh sistem Lightning Detector

Pemetaan dan analisis kerapatan meliputi seluruh wilayah kabupaten dan kota di Jabodetabek. Secara garis besar, penelitian dilakukan berdasarkan pemetaan petir yang di-overlay dengan peta wilayah Jabodetabek pada periode musim tiga bulanan yaitu musim penghujan Desember-Januari-Februari (DJF), musim peralihan Maret-April-Mei (MAM), dan musim kemarau Juni-Juli-Agustus (JJA). Analisis sebaran petir bulanan dihubungkan dengan fenomena atmosfer skala global maupun regional yang terjadi seperti Dipole Mode (DM), Madden Julian Oscilation (MJO), Northerly Cold Surge (NCS) dan El Nino - La Nina pada tahun 2016. Dari penelitian Paski (2017), fenomena cuaca regional seperti NCS memberi dampak yang besar terhadap cuaca di wilayah Indonesia bagian barat terutama di Laut Jawa dan wilayah Jawa bagian utara [11]. Selanjutnya dilakukan validasi distribusi sambaran petir yang terjadi karena pertumbuhan awan Cumulonimbus dilakukan dengan menganalisis citra radar cuaca BMKG. Produk yang digunakan merupakan produk ACM dari radar cuaca EEC Tangerang.

\section{HASIL DAN PEMBAHASAN}

Analisa pemetaan petir dilakukan secara spasial dengan memetakan kerapatan sambaran petir di wilayah Jabodetabek pada periode musim tiga bulanan yaitu musim penghujan Desember-Januari-Februari (DJF), musim peralihan Maret-April-Mei (MAM), dan musim kemarau Juni-Juli-Agustus (JJA). Analisa secara temporal dihubungkan dengan indeks-indeks yang digunakan untuk mengindikasi terjadinya fenomena cuaca sinoptik seperti Indeks Nino 3.4 dan Dipole Mode Index.

Berdasarkan pemetaan distribusi sambaran petir CG postif dan negatif per musim tahun 2016 umumnya tersebar di seluruh wilayah Jabodetabek (Gambar 2). Hasil analisis sambaran petir menunjukan bahwa daerah rawan petir terjadi pada daerah pegunungan dan daerah laut Jawa perairan utara Jabodetabek. Faktor topografi sangat berperan dalam pembentukan awan . Orografi sangat berpengaruh dalam pembentukan awan Cumulonimbus di wilayah pegunungan dan konveksi udara berpengaruh pada pembentukan awan Cumulonimbus di perairan.

Dari gambar 2 terlihat bahwa kota-kota di pinggiran Jakarta lebih rentan dengan sambaran petir dibandingkan wilayah Jakarta. Hal ini disebabkan oleh faktor ketinggian permukaan yang menunjukan bahwa wilayah Jakarta seperti sebuah cekungan dengan wilayah yang lebih tinggi mengelilinginya. Selain itu, wilayah sekitaran Jakarta juga merupakan sentra industry yang terdapat banyak pabrik-pabrik besar yang sangat rentan dengan sambran petir. 
Hubungan antara kerapatan petir dan ketinggian mengindikasikan korelasi positif. Semakin tinggi posisi suatu wilayah semakin tinggi aktivitas sambaran petirnya. Untuk wilayah Jabodetabek, daerah gunung Salak di wilayah Bogor merupakan daerah dengan kerapatan petir yang paling tinggi. Petir terjadi dengan intensitas kejadian yang konsisten dan berbanding lurus dengan ketinggian di wilayah Bogor (lihat gambar 2). Hubungan ini lebih dikarenakan oleh faktor topografi yang meyebabkan pertumbuhan awanawan konvektif akibat proses orografi, yaitu proses naiknya massa udara yang diakibatkan oleh kontur dataran tinggi/gunung sehingga tumbuh menjadi awan-awan konvektif.

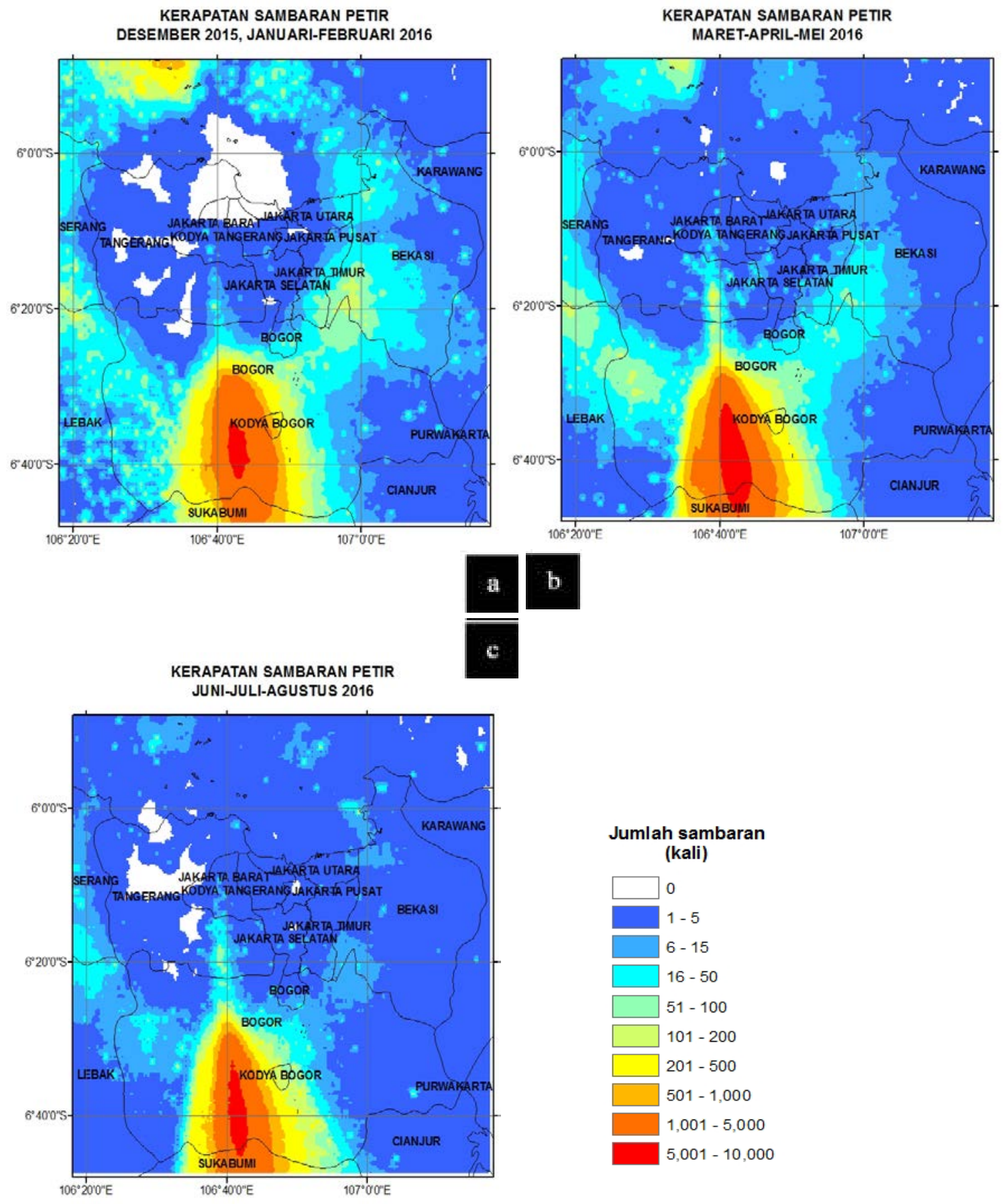

GAMBAR 2. Analisis sambaran petir CG di Jabodetabek tahun 2016 musim penghujan DJF (a), musim peralihan MAM (b), dan kemarau JJA (c) 
Berdasarkan peta kerapatan sambaran petir tahun 2016 pada musim penghujan dari Desember 2015 hingga Februari 2016, kerapatan sambaran petir terkonsentrasi di wilayah Bogor dengan intensitas tertinggi mencapai 5000 - 10000 kali sambaran pada satu lokasi (lihat gambar 2a). Selain wilayah bogor terdapat konsentrasi sambaran petir namun dengan intensitas yang lebih sedikit berkisar 200 - 500 kali sambaran per lokasi. Hal itu terjadi di wilayah laut Jawa, daerah sekitar barat Tangerang, dan wilayah Bekasi. Intensitas sambaran petir di wilayah sekitar Jakarta tampak lebih bayak dibandingkan wilayah Jakarta. Terdapat beberapa wilayah di Jakarta yang tidak terdapat aktivitas sambaran petir pada musim penghujan yaitu sebagian wilayah Jakarta bagian Utara.

Berdasarkan peta kerapatan sambaran petir pada musim peralihan dari Maret hingga April 2016, kerapatan sambaran petir masih terkonsentrasi di wilayah Bogor dengan intensitas tertinggi mencapai 5000 - 10000 kali sambaran pada satu lokasi namun dengan cakupan yang lebih luas dibanding musim penghujan (lihat gambar 2b). Selain wilayah Bogor juga terdapat konsentrasi sambaran petir dengan intensitas yang lebih sedikit berkisar 200 - 500 kali sambaran per lokasi. Hal itu terjadi di wilayah laut Jawa, daerah sekitar barat Tangerang. Pada musim peralihan wilayah di Jakarta yang tidak terdapat aktivitas sambaran petir pada sudah mulai tidak tampak, namun masih ada beberapa wilayah dengan luasan yang sempit yang tidak terjadi aktivitas sambaran petir.

Pada musim kemarau (lihat gambar 2c), kerapatan sambaran petir masih terkonsentrasi di wilayah Bogor dengan intensitas tertinggi mencapai 5000 - 10000 kali sambaran pada satu lokasi namun dengan cakupan yang lebih sempit dibanding musim penghujan. Selain itu sudah tidak terdapat konsentrasi sambaran petir dengan intensitas yang lebih sedikit berkisar 200 - 500 kali sambaran per lokasi. Terdapat beberapa wilayah di Jakarta yang tidak terdapat aktivitas sambaran petir pada musim penghujan yaitu sebagian wilayah Jakarta bagian Barat. Intensitas sambaran petir di wilayah sekitar Jakarta mulai tampak sama dengan sambaran petir wilayah Jakarta. Intensitas sambaran petir di wilayah Laut jawa juga sudah mulai berkurang dan tidak seperti musim-muim sebelumnya.

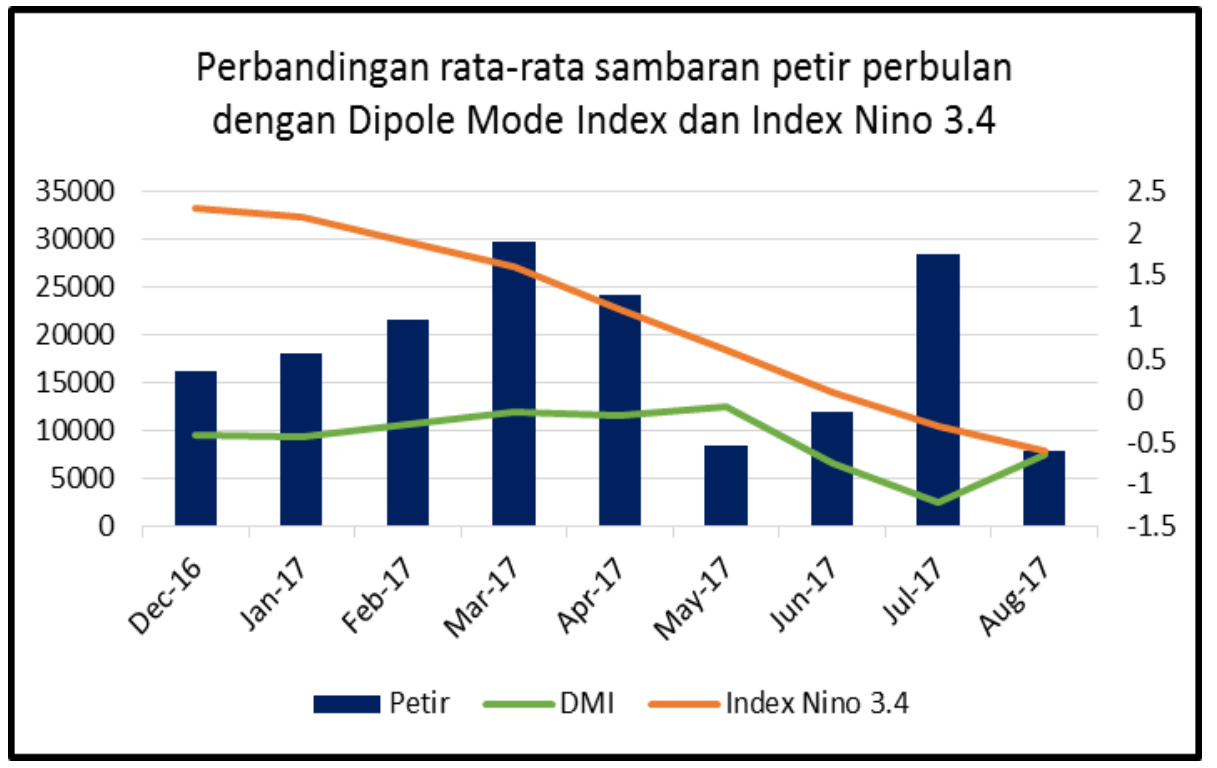

GAMBAR 3. Hubungan sambaran petir CG di Jabodetabek tahun 2016 dengan DMI dan Indeks Nino 3.4

Analisa temporal dilakukan dengan melihat grafik hubungan antara jumlah sambaran petir CG dengan fenomena atmosfer skala global dan regional. Grafik dibuat dengan data jumlah sambaran petir CG, Indeks Nino 3.4 dan Dipole Mode Index (DMI) dalam bulanan mulai dari Desember 2015 hingga Agustus 2016 seperti yang terlihat pada gambar 3. Nilai negatif pada Dipole Mode Index (DMI) menyatakan bahwa dari Samudra Hindia sebelah timur yang berarti bagian barat Indonesia lebih hangat dibandingkan Samudra Hindia sebelah barat. Hal ini menyebabkan wilayah Indonesia bagian barat berpotensi naiknya 
curah hujan [12]. Sama halnya dengan DMI, Indeks Nino 3.4 bernilai negative menyatakan terjadinya La Nina di wilayah Indonesia yang menyebabkan naiknya potensi hujan.

Dari hasil analisa menunjukan bahwa pada awal tahun 2016 yang merupakan periode musim hujan masih terjadi fenomena El Nino di wilayah Indonesia sehingga pertumbuhan awan konvektif tidak maksimal dan menyebabkan berkurangnya intensitas sambaran petir meskipun DMI bernilai negatif. Pada bulan Februari 2016 juga terjadi super posisi Madden Julian Oscillation (MJO) dan Northerly Cold Surge (NCS) di awal bulan Maret pada tanggal 2- 8 Maret 2016 dengan MJO berlangsung hingga dasarian ketiga.

Pada Maret - April yang merupakan periode musim peralihan, intensitas petir cenderung lebih banyak dari pada di musim penghujan, selain karena kekuatan El Nino sudah melemah dan DMI yang masih bernilai negatif cenderung normal ( $>-0.4)$, Pada musim peralihan cenderung awan-awan yang terbentuk merupakan awan-awan konvektif yang tinggi. Hal ini disebabkan karean cuaca yang cenderung lebih labil dengan massa udara dingin di lapisan atas dan massa udara lebih hangat dekat permukaan. MJO juga terjadi pada rentang $15-23$.

Pada periode musim kemarau, seharusnya potensi pertumbuhan awan konvektif tidak terlalu signifikan sehingga sambaran petir berkurang. Terjadi anomali pada bulan Juli 2016 dimana jumlah sambaran petir terjadi lebih banyak. Hal ini terjadi dikarenakan DMI bernilai kurang dari -1 yang menandakan bahwa Samudra Hindia sebelah selatan cenderung lebih hangat yang menyebabkan potensi pertumbuhan awan konvektif lebih besar.

Untuk melihat keakuratan data kerpatan sambaran petir yang terekam, dilakukan validasi data sambaran petir dengan data hasil citra radar cuaca. Validasi dilakukan dengan mengambil kasus sambaran petir total sambaran petir terbayak selama satu hari yaitu pada tanggal 28 Februari 2016 dengan data terekam sebanyak 48812 sambaran sehari. Sebagai data pembanding adalah data radar cuaca menggunakan produk ACM 24 jam dari radar cuaca EEC Tangerang yang memiliki radius hingga 250 km.

Pemilihan produk ACM sebagai pembanding mengacu pada hasil penelitian Fansyuri dan Mustofa (2012) yang menyatakan hubungan korelasi antara petir dengan hujan dengan menggunakan metode Spearman mencapai 0.881, sehingga dapat digunakan sebagai data banding. Dari hasil analisa menunjukan data peta kerapatan sambaran petir CG di Jabodetabek perhari (Gambar 4a) jika divalidasi dengan produk ACM 24 jam radar cuaca Tangerang (Gambar 4b) pada tanggal 28 Februari 2016 memiliki pola kecendrungan yang sama. Pola kerapatan sambaran petir di daerah Bogor yang memliki intensitas tinggi dapat terlihat pada pola total curah hujan pada produk ACM dari radar cuaca EEC.

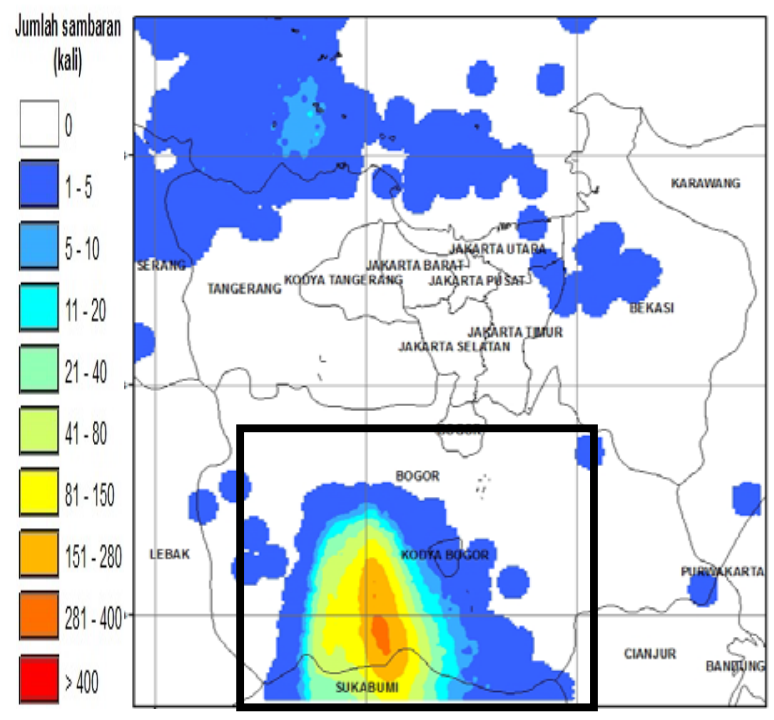

(a)

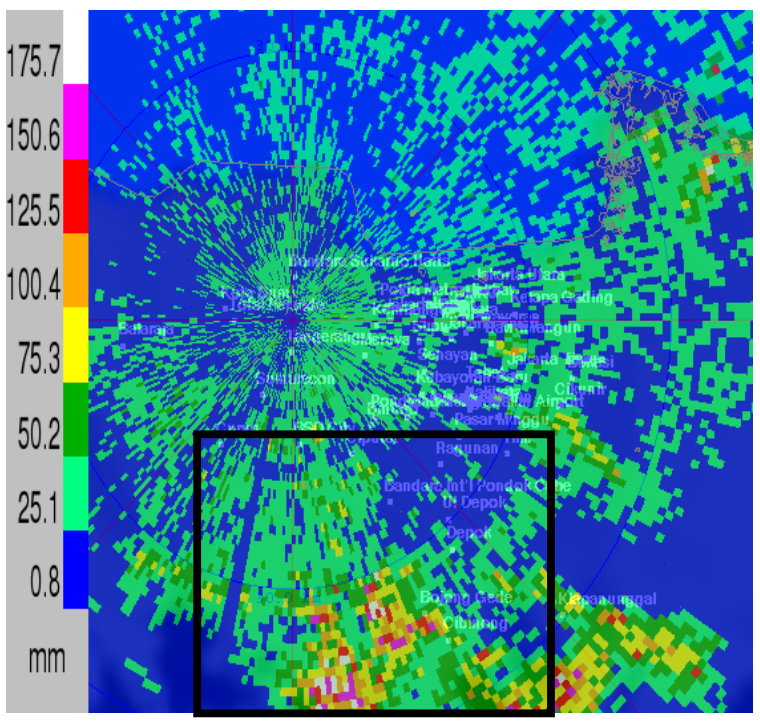

(b)

Gambar 4. Analisis sambaran petir CG di Jabodetabek perhari (a) dan produk ACM 24 jam radar cuaca Tangerang (b) pada tanggal 28 Februari 2016 


\section{SIMPULAN}

Dari beberapa metode analisis yang dilakukan pada penelitian ini, dapat ditarik beberpa kesimpulan. Secara spasial, kerapatan sambaran petir CG umumnya terjadi di wilayah Bogor yang merupaka daerah dataran tinggi dan daerah di perairan laut Jawa utara Jabodetabek. Intensitas tertinggi terjadi pada periode musim peralihan yaitu pada bulan Maret - April - Mei tahun 2016. Secara temporal, intensitas sambaran petir perbulan menunjukan adanya hubungan yang erat antara total sambaran petir dengan fenomena atmosfer seperti DMI, El Nino - La Nina, MJO dan NCS. Pada musim perlihan, intensitas sambaran petir tertinggi pada bulan Maret. Sedangkan dari hasil validasi data kerapatan sambaran petir jika dibandingkan dengan data hasil produk radar cuaca BMKG menunjukan adanya pola yang sama untuk sebaran sambaran petir dan awan hujan. Diharapakan hasil penelitian dapat dijadikan acuan untuk penelitian yang lebih lanjut.

\section{UCAPAN TERIMAKASIH}

Ucapan terima kasih penulis sampaikan untuk rekan kerja di Stasiun Geofisika Tangerang yang telah banyak membantu menyediakan data penelitian. Serta, ucapan terima kasih kepada rekan di Sub-bidang Citra Radar BMKG yang telah menyediakan data yang digunakan dalam penelitian ini.

\section{REFERENSI}

[1] B. Tjasyono, Meteorologi Indonesia I. Badan Meteorology dan Geofisika, Jakarta: BMG, 2006.

[2] J. Huang, and M. B. McElroy, "Contributions of the Hadley and Ferrel Circulations to the Energetics of the Atmosphere over the Past 32 Year,” Journal of Climate 27 (7): 2656-2666, 2004 (doi:10.1175/jcli-d-1300538.1).

[3] M. Husni, “Mengenal Bahaya Petir,” Jurnal Meteorologi dan Geofisika. Vol 3. No. 4, Jakarta: BMKG, 2002.

[4] G. H. Fansury, dan M. A. Mustofa, "Hubungan Aktivitas Petir Cloud-to-Ground dengan Curah Hujan di Bogor”. Bandung : Institut Teknologi Bandung, 2012.

[5] Zajac, B., et all, "Lightning Meteorology II: An Advanced Course on Forecasting with Lightning Data," Preprint, 21st Conf. on Severe Local Storms, Amer. Meteor. Soc., San Antonio, TX, 438-441, 2002.

[6] Pratama, I., P., D. dan P. K. G. A Negara, “Analisis Spasial dan Temporal Sambaran Petir CG di Wilayah Jabodetabek tahun 2009-2015”, 2006.

[7] O. Pinto,, I. R. C. A. Pinto, D. R. de Campos, and K. P. Naccarato, "Climatology of large peak current cloud-to-ground lightning flashes in southeastern Brazil,” J. Geophysics, 2009. (doi:10.1029/2009JD012029).

[8] W. Xu, "Precipitation and convective characteristics of summer deep convection over East Asia observed by TRMM,” Monthly Weather Review,141, 1577-1592, 2013 (doi:10.1175/MWR-D-12-00177.1.)

[9] Y. Luo, H. Wang, R. Zhang, W. Qian, and Z. Luo, “Comparison of rainfall characteristics and convective properties of monsoon precipitation systems over South China and the Yangtze and Huai River basin,” J. Climate, 26, 110-132, 2013. (doi:10.1175/JCLI-D-1200100.1. 
[10] M. I. R. Tinmaker, K. Ali, and S. D. Pawar, "Thunderstorm Electrical Parameters vis-a-vis Rainfall and Surface Air Temperatures over a Tropical Inland Station,” India. Journal of the Meteorological Society of Japan 88 (6): 899-908, 2010.

[11] J. A. I. Paski, A. Sepriando dan D. A. S. Pertiwi., 2017. "Identifikasi Northerly Cold Surge Memanfaatkan Numerical Weather Prediction (NWP) dan Teknik RGB Airmass pada Satelit Himawari-08,” Pada Seminar Nasional Sains Atmosfer, Bandung, Lapan, 2017.

[12] N.H. Saji, B.N. Goswami, P.N. Vinayachandran, and T.Yamagata, “A Dipole Mode in the Tropical Indian Ocean”, Nature, 401, 360-363, 1999. 